International Journal of Current Microbiology and Applied Sciences

ISSN: 2319-7706 Volume 6 Number 8 (2017) pp. 2304-2309

Journal homepage: http://www.ijcmas.com

Original Research Article

https://doi.org/10.20546/ijcmas.2017.608.271

\title{
Molecular Confirmation of Rhipicephalus haemaphysaloides Infesting Ruminants in Wayanad, Kerala, India
}

\author{
Murikoli Nimisha ${ }^{1}$, Reghu Ravindran ${ }^{1 *}$, Pradeep R. Kariyappa ${ }^{1}$, B. Mallappa Amrutha ${ }^{1}$, \\ Prashant Somalingappa Kurbet ${ }^{1}$, Karapparambu Gopalan Ajith Kumar ${ }^{1}$, \\ Anju Varghese', Chundayil Kalarikkal Deepa ${ }^{1}$ and Sanis Juliet ${ }^{2}$ \\ ${ }^{1}$ Department of Veterinary Parasitology, College of Veterinary and Animal Sciences, Pookode, \\ Lakkidi, P.O., Wayanad-673576, Kerala, India \\ ${ }^{2}$ Department of Veterinary Pharmacology and Toxicology, College of Veterinary and Animal \\ Sciences, Pookode, Lakkidi, P.O., Wayanad-673576, Kerala, India \\ *Corresponding author
}

\section{A B S T R A C T}

Keywords

Rhipicephalus

haemaphysaloides,

PCR, Phylogeny,

Wayanad, Kerala.

Article Info

Accepted:

21 June 2017

Available Online:

10 August 2017
Rhipicephalus haemaphysaloides is a prevalent multi host tick species with high vector potential in south India. There are several reports based on morphological identification of the tick species from various parts of the country. However, there were limited attempts for molecular confirmation of this tick species. In the present study, the presence of $R$. haemaphysaloides in Wayanad, Kerala was confirmed by polymerase chain reaction based on amplification of mitochondrial $16 \mathrm{~S}$ rRNA gene and V4 region of $18 \mathrm{~S}$ rRNA gene. Two tick samples, one engorged on a bovine male calf of Pookode, Wayanad and other engorged on a sambar deer in Meppadi were used for the study. Phylogeny based on 16S rRNA and 18S rRNA of $R$. haemaphysaloides revealed genetic relatedness with Chinese isolates of the tick species.

\section{Introduction}

Parasitic diseases are one of the major obstacles for the health of the animals, thereby causing severe economic constraints globally Ticks are the obligate haematophagousecto parasites of both livestock and humans. They were rank second after mosquitoes as vectors of human diseases. Ticks play an important role in the transmission of various pathogens like bacteria, viruses, protozoa and helminths, many of which have zoonotic significance (de
La Fuente et al., 2008). Tick infestation results in direct damages like reduction in milk yield and live weight and indirect effects due to pathogen transmission and toxicosis resulting in paralysis, irritation and allergy (Aktas, 2014).

The direct injuries due to ixodid ticks are severe in tropical climate (Ghosh and Nagar, 2014). There is a recent surge in studies regarding tick and tick borne diseases due to 
the changes in tick distribution mainly contributed by the changes in climate (Jaensonet al., 2009). According to Burger et al., (2014), 904 tick species were identified globally. Almost 80 per cent of the tick species comes under the family Ixodidae or hard ticks (705 species). Family Argasidae or soft ticks contain 198 species and one under the family Nuttalliellidae.

India is home for approximately 109 tick species, under 12 genera (Ghosh et al., 2007).The climatic conditions in India are highly favorable for the propagation of ticks. Most predominant tick species identified in India belong to the genus Rhipicephalus and Hyalomma (Ghosh et al., 2007).

The prevalence of Rhipicephalus haemaphysaloides based on morphological identification was recorded from various parts of India including Kerala (Geevarghese and Dhanda, 1995; Rajendran and Hafeez, 2003; Prakasan and Ramani, 2007; Soundararajan et al., 2014). However, they were no studies regarding the molecular confirmation of the tick species. In the present study, molecular confirmation of $R$. haemaphysaloides was performed using ticks collected from Wayanad, a northern district of Kerala.

\section{Materials and Methods}

Tick samples were collected froma bovine male Calffrom College of Veterinary and Animal Sciences, Pookode, Wayanad. Another isolate was collected from a sambar deer from Meppadi, Wayanad. Ticks were morphologically identified (Arthur, 1960) and stored in $-80^{\circ} \mathrm{C}$ until RNA extractionwas performed. RNA extraction was done using RNeasy Mini Kit (Qiagen, Netherlands) based on the manufacture's protocols. Synthesis of cDNA was performed by Revert Aid $\mathrm{H}$ minus First strand cDNA synthesis kit (Thermo Scientific, USA). This cDNA was used as template for the polymerase chain reaction (PCR). Molecular confirmation of tick species was done by PCR amplification of mitochondrial 16S rRNA gene and V4 region of 18S rRNA gene (Crampton et al., 1996; Kumar et al., 2011). The primer sequences for PCR amplification are mentioned in table 1.

Amplified PCR products were analyzed by gel electrophoresis using 1.5 per cent agarose gel. PCR amplified products were sequenced at Sci. Genome Pvt. Ltd., Cochin and the sequence data were BLAST analyzed.

Phylogenetic analysis was performed for both $16 \mathrm{~S}$ rRNA and 18S rRNA genesby Neighborjoining tree method using Mega 7. Nucleotide sequences were aligned by Clustal $\mathrm{W}$ for analysis. Akaike information criterion implemented in MEGA 7.0 was used to determine the best fitting models. The evolutionary distances were computed using Tamura 3-parameter method and JukesCantor method for 16S rRNA and 18S rRNA respectively.

\section{Results and Discussion}

Tick isolates from Pookode and Meppadi were morphologically identified as $R$. haemaphysaloides. Molecular analysis of tick mitochondrial16S rRNA gene of Pookode and Meppadi isolates revealed 95 per cent and 93 per cent identity respectively with $R$. haemaphysaloides (AY972534) from China.

BLAST analysis of $18 \mathrm{~S}$ rRNA sequence of Pookode and Meppadi isolate showed 96 per cent and 100 per cent identity respectively with $R$. haemaphysaloides (DQ839552) from China. The sequences were submitted to Gen Bankto obtain accession numbers. Pookode isolate was assigned with accession numbers, KU895511 and KU895510 for 16S rRNA and $18 \mathrm{~S}$ rRNA respectively. Similarly, Meppadi isolate was assigned with accession numbers 
MF351994 and MF351848 for 16S rRNA and $18 \mathrm{~S}$ rRNA respectively.

Phylogenetic analysis of mitochondrial16S rRNA revealed that both Pookode and Meppadi isolates of ticks were genetically closely related. Also, both shared identity with Chinese and Thailand isolates of $R$. haemaphysaloides. Based on evolutionary analysis of 18S rRNA, Pookode isolate of $R$. haemaphysaloides was more ancestral to both Meppadi and Chinese isolates (Figs. 1 and 2).

In the present study, the presence of $R$. haemaphysaloides in Wayanad was confirmed by molecular techniques. $R$. haemaphysaloidesis usually prevalent in Oriental, Australasian and Palearctic zoogeographic regions with wide host range. The usual hosts of these ticks are birds and mammals including humans (Guglielmone et $a l ., 2014) . R$. haemaphysaloides is one of the most abundant cattle ticks in Sri Lanka (Diyes and Rajakaruna, 2015). Rajendran and Hafeez (2003) reported a prevalence of 3.29 per cent for $R$. haemaphysaloides among crossbred cattle of Andhra Pradesh. Soundararajan et al., (2014) recorded a prevalence of 3.13 per cent in goats of Tamil Nadu. Prakasan and Ramani (2007) reported $R$. haemaphysaloides from cattle, buffalo, goat and pigs in Kerala.

Fig.1 Molecular phylogeny based on 16S r RNA. The evolutionary history was inferred using the Neighbor-Joining method. The optimal tree with the sum of branch length $=0.56035004$ is shown. The percentage of replicate trees in which the associated taxa clustered together in the bootstrap test (1000 replicates) is shown next to the branches. The tree is drawn to scale, with branch lengths in the same units as those of the evolutionary distances used to infer the phylogenetic tree. The evolutionary distances were computed using the Tamura 3-parameter method and are in the units of the number of base substitutions per site. The rate variation among sites was modeled with a gamma distribution (shape parameter $=1$ ). The analysis involved 14 nucleotide sequences

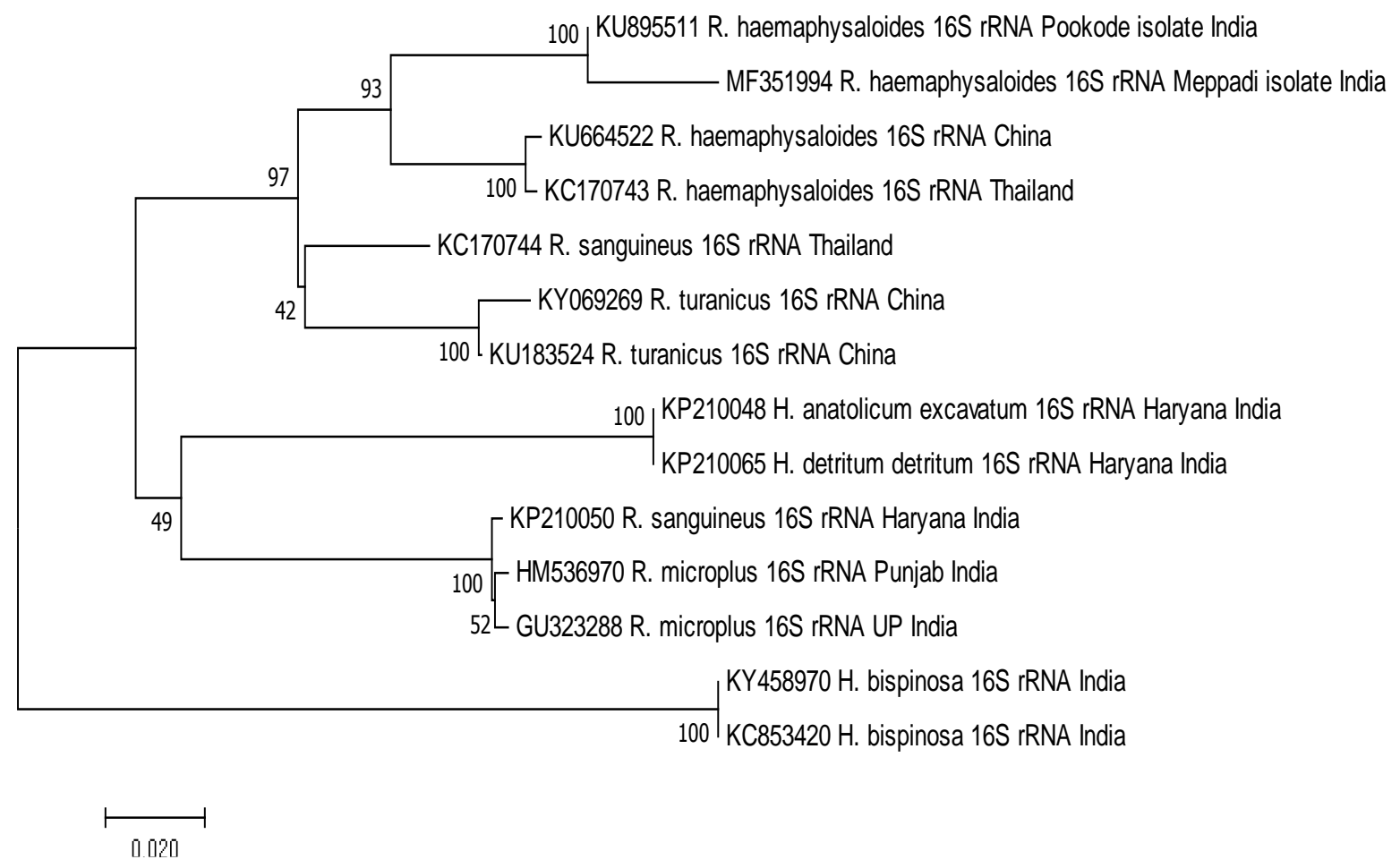


Fig.2 Molecular phylogeny based on 18S rRNA. The evolutionary history was inferred using the Neighbor-Joining method. The optimal tree with the sum of branch length $=1.67598566$ is shown. The percentage of replicate trees in which the associated taxa clustered together in the bootstrap test (1000 replicates) is shown next to the branches. The tree is drawn to scale, with branch lengths in the same units as those of the evolutionary distances used to infer the phylogenetic tree. The evolutionary distances were computed using the Jukes-Cantor method and are in the units of the number of base substitutions per site. The analysis involved 11 nucleotide sequences

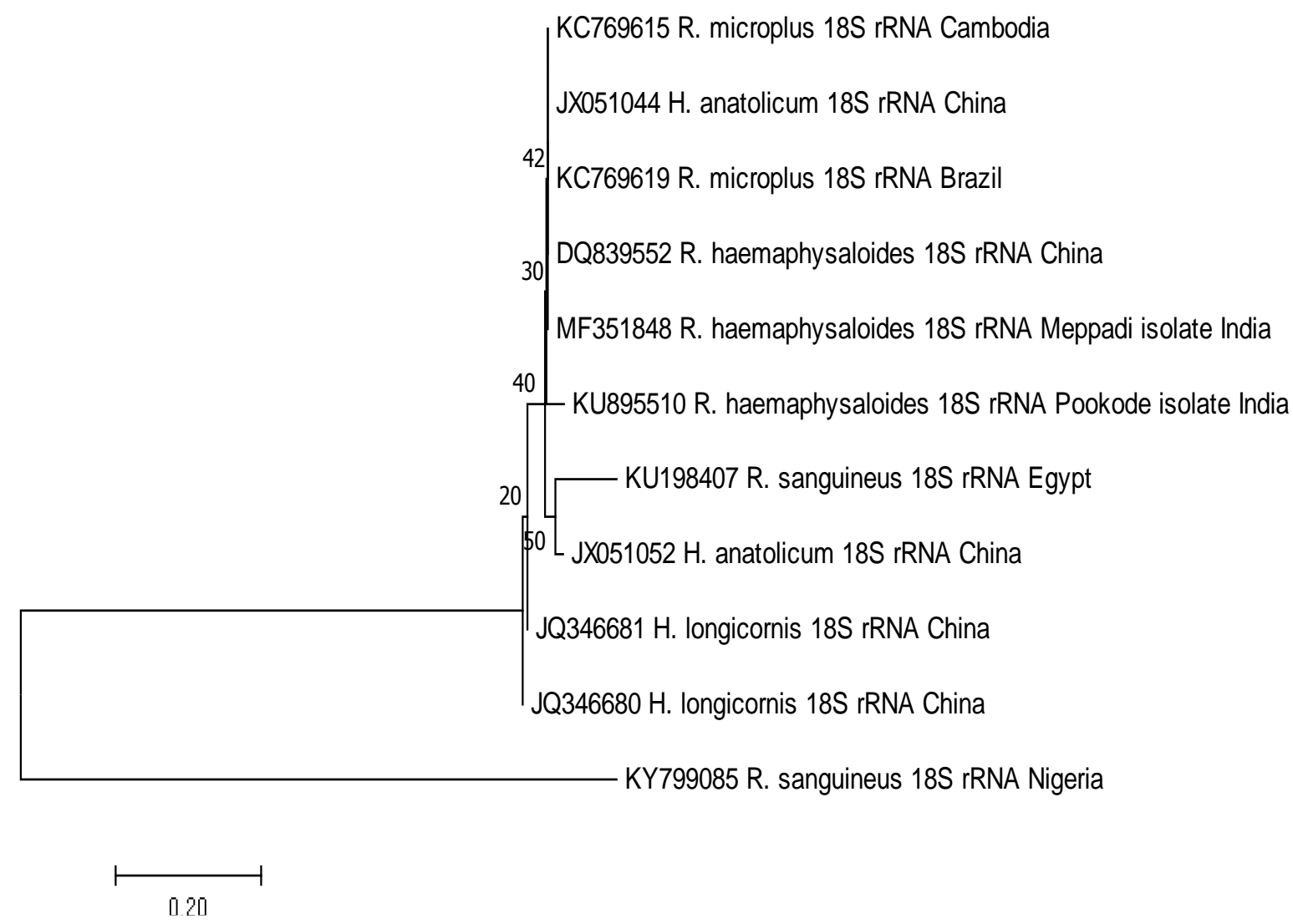

Table.1 Primers used for amplification of 16S r RNA and 18 S rRNA from ticks

\begin{tabular}{|l|l|l|c|l|}
\hline $\begin{array}{l}\text { Sl. } \\
\text { No. }\end{array}$ & \multicolumn{1}{|c|}{ Gene } & \multicolumn{1}{c|}{ Primers } & $\begin{array}{l}\text { Amplicon } \\
\text { length }\end{array}$ & Reference \\
\hline Ticks & $\begin{array}{l}\text { 16S ribosomal } \\
\text { RNA gene TIR }\end{array}$ & $\begin{array}{l}\text { Forward-5 } \\
\text { CCGGTCTGAACTCAGATCAAGT 3' } \\
\text { Reverse- 5 } \\
\text { GCTCAATGATTTTTTAAATTGCTG3, }\end{array}$ & 450bp & $\begin{array}{l}\text { Kumar } \text { et } \\
\text { al., (2011) }\end{array}$ \\
\hline Ticks & $\begin{array}{l}\text { V4 region of 18S } \\
\text { ribosomal RNA } \\
\text { gene TV4 }\end{array}$ & $\begin{array}{l}\text { Forward- 5' } \\
\text { GGAGGGCAAGTCTGGTGC 3, } \\
\text { Reverse- 5, } \\
\text { CCATACAAATGCCCCCGTCTG 3 }\end{array}$ & 338bp & $\begin{array}{l}\text { et al., } \\
(1996)\end{array}$ \\
\hline
\end{tabular}


$R$. haemaphysaloides is having both medical and veterinary significance as they can act as vector for various pathogens. Laboratory studies revealed their role in the transmission of Rickettsia (Hsu et al., 2011). Tsui et al., (2007) detected spotted fever group rickettsial organism in $R$. haemaphysaloides using molecular methods in Taiwan. Experimental transtadial transmission of Babesia microti through $R$. haemaphysaloides in southern China was also reported (Li et al., 2016). Bhat et al., (1978) confirmed the role of $R$. haemaphysaloides for the transmission of Kyasanur forest disease (KFD). Thus, the presence of $R$. haemaphysaloides in Wayanad and its wide vector potential indicated the increased risk for both animals and humans in the area.

\section{Acknowledgement}

Financial supports from Indian Council of Agricultural Research through research projects (NAIP/Com-4/C2066/2007-2008, NFBSFARA/BSA-4004/2013-14, NASF/ ABA-6015/2016-17, No.7 (2)/- 2011- EPD), Department of Animal Husbandry, Kerala (B2-8401/08/Plg) and Kerala State Council for Science, Technology and Environment (022/YIPB/ KBC/2013/CSTE, 01014/SARD/13/CSTE) are thankfully acknowledged.

\section{References}

Arthur, D. R. 1960. Ticks: A monograph of the Ixodidae part $\mathrm{V}$. On the genera Dermacentor, Anocentor, Cosmiomma, Boophilusand Margaropus, Cambridge UniversityPress, London. 251pp.

Aktas, M. 2014. A survey of ixodid tick species and molecular identification of tick-borne pathogens. Vet. Parasitol, 200:276-283.

Bhat, H. R., Naik, S. V., Ilkal, M. A. and Banerjee, K. 1978. Transmission of
Kyasanur Forest disease virus by Rhipicephalus haemaphysaloides ticks. ActaVirol, 22: 241-244.

Burger, T. D., Shao, R., Labruna, M. B. and Barker, S. C. 2014. Molecular phylogeny of soft ticks (Ixodida: Argasidae) inferred from mitochondrial genome and nuclear rRNA sequences. Ticks Tick Borne Dis., 5:195-207.

Crampton, A., Mckay, I. and Barker, S. C. 1996. Phylogeny of ticks (Ixodida) inferred from nuclear ribosomal DNA. Int. J. Parasitol., 26: 511-517.

De La Fuente, J., Estrada-Pena, A., Venzal, J.M., Kocan, K. M. andSonenshine, D. E. 2008. Overview: Ticks as vectors of pathogens that cause disease in humans and animals. Front. Biosci, 13: 69386946.

Diyes, G. C. P. and Rajakaruna, R. S. 2015. Diversity and distribution of tick species infesting goats with two new host records from Sri Lanka. J.Natn.Sci.Foundation Sri Lanka, 43 (3): 225-234.

Geevarghese, G. and Dhanda, V. 1995. Ixodid ticks of Maharashtra state, India.Acarologia, 36(4): 309-313.

Ghosh, S., Azhahianambi, P. and Yadav, M. P. 2007. Upcoming and future strategies of tick control: a review. J. Vector Borne. Dis., 44: 79-89.

Ghosh, S. and Nagar, G. 2014. Problem of ticks and tick-borne diseases in India with special emphasis on progress in tick control research: A review. $J$. Vector Borne Dis., 51: 259-270.

Guglielmone, A. A., Robbins, R. G., Apanaskevich, D. A., Petney, T. N., Estrada-Peña, A. and Horak, I. G. 2014. The hard ticks of the world (Acari: Ixodida:Ixodidae). Springer, 8: 738 pp.

Hsu, Y. M., Lin, C. C., Chomel, B. B., Tsai, K. H., Wu, W. J., Huang, C. G. and Chang, C. C. 2011. Identification of Rickettsia felisin fleas but not ticks on 
stray cats and dogs and the evidence of Rickettsia rhipicephalionly in adult stage of Rhipicephalus sanguineus and Rhipicephalus haemaphysaloides. Comp. Immunol. Microbiol. Infect. Dis., 34: 513-518.

Jaenson, T. G., Eisen, L., Comstedt, P., Mejlon, H. A., Lindgren, E., Bergström, S. and Olsen, B. 2009. Risk indicators for the tick Ixodesricinusand Borreliaburgdorferisensulato in Sweden. Med. Vet. Entomol, 23 (3): 226-237.

Kumar, R., Paul, S., Kumar, S., Sharma, A. K., Gupta, S., Rawat, A. K. S., Chaudhuri, P., Ray, D. D. and Ghosh, S. 2011. Detection of specific nucleotide changes in the hypervariable region of 16S rDNA gene of Rhipicephalus (Boophilus) microplus and Hyalomma analoticum anatolicum. Indian J. Anim. Sci., 81: 1204-1207.

Li, L., Zhu, D., Zhang, C., Zhang, Y. and
Zhou, X. 2016. Experimental transmission of Babesiamicroti by Rhipicephalus haemaphysaloides. Parasit. Vectors, 9: 231-236.

Prakasan, K. and Ramani, N. 2007. Tick parasites of domestic animals of Kerala, South India. Asian J. Anim. Vet. Adv., 2(2): 74-80.

Soundararajan, C., Latha, B. R. and Pandian, S. S. 2014. Prevalence of tick infestation in goats under different system of management. Int. J. Agric. Sci. \& Vet. Med., 2(3):4-9.

Rajendran, C. and Hafeez, M. D. 2003. Prevalence of ixodid ticks on crossbred cattle in and around Tirupati. J. Vet. Parasitol, 17: 147-149.

Tsui, P., Tsai, K., Weng, M., Hung, Y., Liu, Y., Hu, K., Lien, J., Lin, P., Shaio, M., Wang, H. and Ji, D. 2007. Molecular detection and characterization of spotted fever group Rickettsia in Taiwan. Am. J. Trop. Med. Hyg., 77(5): 883-890.

\section{How to cite this article:}

Murikoli Nimisha, Reghu Ravindran, Pradeep R. Kariyappa, B. Mallappa Amrutha, Prashant Somalingappa Kurbet, Karapparambu Gopalan Ajith Kumar, Anju Varghese, Chundayil Kalarikkal Deepa and Sanis Juliet. 2017. Molecular Confirmation of Rhipicephalus haemaphysaloides Infesting Ruminants in Wayanad, Kerala. Int.J.Curr.Microbiol.App.Sci. 6(8): 2304-2309. doi: https://doi.org/10.20546/ijcmas.2017.608.271 